\title{
Pemilihan Teknologi PLTSa di Kota Yogyakarta (Studi Kasus: TPA Piyungan Yogyakarta)
}

\author{
Afrizal Abdi Musyafiq ${ }^{1 *}$, Hilman Zarory ${ }^{2}$, Vicky Prasteia ${ }^{3}$ \\ ${ }^{1}$ Jurusan Teknik Elektro, Fakultas Teknologi Informasi, Universitas Nahdlatul Ulama, Yogyakarta \\ ${ }^{2}$ Jurusan Teknik Elektro, Fakultas Teknologi Informasi, Universitas Nahdlatul Ulama, Yogyakarta \\ ${ }^{3}$ Jurusan Teknik Elektronika, Politeknik Negeri Cilacap, Cilacap \\ ${ }^{1} \mathrm{Jln}$. Lowanu, Kota Yogyakarta, 55162, Indonesia \\ 2,Jln. Lowanu, Kota Yogyakarta, 55162, Indonesia \\ 3,Jln. Dr. Soetomo, Kabupaten Cilacap, 53212, Indonesia \\ email: ${ }^{1}$ afrizal.abdi.m@gmail.com, ${ }^{2}$ hilman.z@unu-jogja.ac.id, ${ }^{3}$ vickyprasetia@pnc.ac.id
}

\begin{abstract}
The city of Yogyakarta is the city of choice for foreign and local tourist destinations. Their arrival also became a problem for the city of Yogyakarta in terms of waste. This is evidenced by the increasing waste generation in the city of Yogyakarta. Yogyakarta City waste is transported to Piyungan landfill every day. Piyungan Landfill has limited availability of land while unlimited amounts of incoming waste every day. Based on the primary data obtained from this study, the average municipal waste in Yogyakarta was 310 tons / day. The solution to this problem is the Waste Power Plant (PLTSa). The benefits of PLTSa to produce electricity can also reduce the volume of waste at the Piyungnan landfill. PLTSa technology certainly has choices in accordance with the characteristics of waste in the Piyungan Landfill. The purpose of this study is to conduct a review of the feasibility of PLTSa technology to be selected by the Grid Analysis (GA) method. First, there is a need for primary and secondary data about the amount of waste generated in the city of Yogyakarta every day. The method used in choosing PLTSa technology in the city of Yogyakarta with a simple random method was continued using the grid analysis method. The results of the calculation and processing of data obtained the right technology for karakersit city waste Yogyakarta is incenerator.
\end{abstract}

Keyword - grid analysis, PLTSa, TPA Piyungan, Yogyakarta City

Abstrak - Kota Yogyakarta merupakan kota pilihan untuk destinasi wisatawan asing maupun lokal. Kedatangan mereka pun menjadi masalah tersendiri bagi Kota Yogyakarta dalam hal persampahan. Hal ini dibuktikan dengan semakin meningkatnya timbulan sampah di Kota Yogyakarta. Sampah Kota Yogyakarta diangkut mennuju TPA Piyungan seetiap harinya. TPA Piyungan sudah mengalami ketersediaan lahan yang terbatas sedangkan jumlah sampah masuk setiap hari tidak terbatas. Berdasarkan data primer yang didapatkan dari penelitian ini adalah rata-rata sampah Kota Yogyakarta yang masuk sebesar 310 ton/hari. Solusi dari permasalahan tersebut adalah Pembangkit Listrik Tenaga Sampah (PLTSa). Manfaat PLTSa menghasilkan listrik juga dapat mereduksi volume sampah di TPA Piyungnan. Teknologi PLTSa tentu ada pilihannya sesuai dengan karaktersitik sampah di TPA Piyungan. Tujuan penelitian ini adalah melakukan tinjauan tentang kelayakan teknologi PLTSa yang akan dipilih dengan metode Grid Analysis (GA). Mula-mula perlu adanya data primer dan sekunder tentang jumlah timbulan sampah di Kota Yogyakarta setiap harinya. Metode yang digunakan dalam memilih teknologi PLTSa di Kota Yogyakarta dengan metode acak sederhana dilanjutkan dengan menggunakan metode grid analysis. Hasil perhitungan dan pengolahan data didapatkan teknologi yang tepat unutk karakersitik sampah kota yogyakarta adalah insinerator.

Kata Kunci - grid analysis, PLTSa, TPA Piyungan, Kota Yogyakarta.

\section{PENDAHULUAN}

Kota-kota besar di indonesia masih mempunyai masalah yang tak kunjung selesai dengan persampahan. Setiap hari potensi timbunan sampah selalu meningkat, hal ini dibuktikan dengan adanya pertambahan jumlah massa sampah yang masuk ke Tempat Pemrosesan Akhir (TPA). Menurut Undang-undang Nomor 18 Tahun 2008 menyebutkan bahwa sampah adalah sisa kegiatan sehari-hari manusia dan/atau proses alam yang berbentuk padat. Sampah secara umum dapat diartikan sebagai limbah atau buangan yang bersifat padat, setengah padat yang merupakan hasil sampingan dari kegiatan perkotaan atau siklus kehidupan manusia, hewan, maupun tumbuh-tumbuhan [1]. Berdasarkan rencana aksi nasional, Indonesia sudah menetapkan perencanaan untuk menurunkan emisi green house gas (GHG) sebesar 26\% dari kegiatan dibidang persampahan pada 2010-2020. Langkah tersebut bisa dilakukan dengan menggunakan pengelolaan limbah berbasis energi (waste to energy) [2]. Pengelolaan waste to energy bisa dikembangkan lagi menjadi Pembangkit Listrik Tenaga Sampah (PLTSa) [3]. PLTSa merupakan salah satu bentuk konversi energi baru terbarukan yang memanfaatkan sampah sebagai bahan baku untuk membangkitkan boiler [4] yang bekerja terhubung dengan turbin dan generator sehingga bisa dihasilkan energi listrik [5].

Kota Yogyakarta menyumbang wilayah sebesar $32,50 \mathrm{~km}^{2}$ atau sebesar $1,02 \%$ dari total wilayah Daerah Istimew Yogyakarta dengan terdiri dari 14 kecamatan dan 45 kelurahan. Batas wilayah Kota Yogyakara sebelah utara adalah Kabupaten Sleman; barat dan timur adalah Kabupaten Sleman dan Kabupaten Bantul; dan utara selatan adalah Kabupaten Bantul. Kota Yogyakarta sekarang ini mempunyai tingkat kepadatan penduduk sekitar $8.964 \mathrm{jiwa} / \mathrm{m}^{2}$, serta merupakan kota dengan destinasi pilihan wisata bagi penduduk lokal maupun mancanegara [6]. Sampah Kota Yogyakarta yang bersumber dari rumah tangga; pasar; sekolah; tempat wisata; industri; dan fasilitas publik lainnya ditampung dulu di Tempat Pembuangan Sampah (TPS) di

*) penulis korespondensi: Afrizal Abdi Musyafiq

Email: afrizal.abdi.m@gmail.com

Afrizal Abdi Musyafiq: Pemilihan Teknologi PLTSa di Kota ... 
tingkat RT kemudian dikumpulkan dengan truk besar berkapastias 6-10 $\mathrm{m}^{3}$ untuk dibawa ke TPA Piyungan yang terletak di Kabupaten Bantul.

TPA Piyungan merupakan tempat Pemrosesan akhir terbesar di Daerah Istimewa Yogyakarta dengan luas 16 ha. TPA Piyungan berada di Dusun Ngablak, Desa Sitimulyo, Kecamatan Piyungan, Kabupaten Bantul. TPA Piyungan menampung sampah-sampah yang bersumber dari tiga wilayah sekaligus yaitu Kota Yogyakarta; Kabupaten Bantul; dan Kabupaten Sleman dengan jam operasional dibuka mulai pukul 07.00-17.00 dan sistem pengukuran massa sampah sudah menggunakan jembatan timbang yang teritnegrasi dengan software untuk akuisisi data setiap harinya selama jam operasional. TPA Piyungan memiliki 3 alat berat untuk membantu pengelolaan sampah dalam menyusun sampah dan tanah dengan metode landfill.

\section{PENELITIAN YANG TERKAIT}

Penelitian terkait pemilihan teknologi PLTSa di TPA Mojorejo Kabupaten Sukoharjo. Kabupaten Sukoharjo menyumbang luas wilayah $1,43 \%$ dari total wilayah Jawa Tengah dengan total 12 kecamatan seluas 466,66 km2. Berdasarkan luas area yang dimiliki Kabupaten Sukoharjo, ternyata cukup mampu mengalokasikan lahan dengan luas yang cukup untuk kebutuhan pengelolaan sampah. Kabupaten Sukoharjo memiliki lahan pembuangan akhir sampah yakni hanya 3,58 ha yang terletak di TPA Mojorejo Desa Mojorejo Kecamatan Bendosari Kabupaten Sukoharjo. Batas wilayah TPA Mojorejo Kabupaten Sukoharjo disisi utara adalah Dukuh Losari dan Dukuh Sambilutung, disisi timur adalah Dukuh Tempurejo, disisi Selatan adalah Desa Menisharjo, dan disisi barat adalah Dukuh Masan. sudah dilakukan dengan hasil teknologi yang terpilih adalah teknologi hidrotermal. Faktor-faktor yang menjadi pertimbangan adlaah luas lahan; kepasitas sampah; dan efisiensi proses. Jumlah massa sampah masuk ke TPA Mojorejo didapatkan rata-rata sebesar 100 ton/hari dengan teknologi PLTSa yang terpilih adalah hidrotermal [1].

\section{A. Survey Lapangan}

\section{METODE PENELITIAN}

Survey lapangan dilakukan untuk mendapatkan data sekunder berupa informasi-informasi yang sudah ada terkait TPA Piyungan. Informasi tersebut didapatkan dari hasil observasi lapangan secara langsung dan wawancara terhadap petugas lapngan TPA Piyungan. Hasil observasi lapangan berupa informasi keadaan TPA Piyungan seperti data pendukung dalam operasional kegiatan proses pengelolaan sampah. Berdasarkan hasil survey lapangan bahwa TPA Piyungan memiliki luas area sekitar 16 ha dan mempunyai 4 petugas yang bekerja sebagai operator kendaraan alat berat dan 2 petugas operator jembatan timbang.

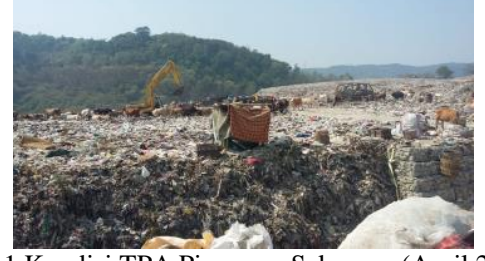

Gbr. 1 Kondisi TPA Piyungan Sekarang (April 2019)

Berdasarkan Gbr. 1 bahwa sistem pengelolaan sampah di TPA Piyungan masih menggunakan sistem landfill. Sistem tersebut sudah tidak mampu untuk mereduksi sampah masuk ke TPA Piyungan yang bersumber dari timbunan-timbunan sampah dari Kota Yogyakarta. Sistem pengelolaan sampah di TPA Piyungan juga dibantu oleh pemulung-pemulung yang mencari sampah rumah tangga untuk dijual kembali kepada pengempul sampah yang lebih besar.

\section{B. Pengambilan Data Sampah Masuk TPA}

Data sampah masuk TPA Piyungan merupakan gabungan data primer dan sekunder yang sudah dikumpulkan dan diolah. Data primer dilakukan dengan pengukuran secara langsung di jembatan timbang terhadap truk sampah yang membawa timbunan sampah Kota Yogyakarta selama 1 bulan penuh. Data sekunder didapatkan dengan melakukan pengambilan data yang sudah direkap oleh petugas operator jembatan timbang selama 11 bulan. Total ada 12 data sampah masuk selama 1 tahun di TPA Piyungan.

Teknik pengambilan data sampel sampah masuk TPA Piyungan dalam penelitian ini adalah probabilty sampling atau pengambilan secara acak, artinya setiap anggota sampel dari populasi memiliki kesempatan dan peluang yang sama. Teknik probabilty sampling yang digunakan adalah metode simple random sampling atau pengambilan acak sederhana. Teknik ini mempunyai kelebihan dan kekurangan tentunya pada setiap penggunaan untuk mengambil data [1].

\section{Metode Grid Analysis (GA)}

Metode GA atau disebut juga metode decision matrix analysisi merupakan salah satu metode dalam proses pengambilan keputusan [7]. Metode GA sangat efektif dalam memilih suatu alternatif karena ada beberapa faktor pertimbangannya. Langkah awal dalam menggunakan metode ini adalah menentukan daftar pertimbangan yang sudah dibuat beserta berbagai pilihannya dan faktor-faktor yang mempengaruhinya. Pilihan-pilihan tersebut disusun dalam lembar kerja dengan label baris berisi "pilihan" dan label kolom berisi "faktor". Langkah berikutnya adalah menyusun dan mengolah tabel yang sudah dibuat dilanjutkan pemberian skor pada pilihan faktor-faktor penting. Pilihan-pilihan tersebut kemudian diberi nilai mulai dari 1 (poor) sampai dengan 5 (excellent). Faktor-faktor tertentu tidak harus memberikan nilai yang berbeda, mungkin bisa jadi bernilai sama [1][8]. Hasil analisa sampel sampah yang sudah dilakukan dapat digunakan sebagai faktor pertimbangan. Karakteristik sampah di TPA Piyungan sesuai dengan proses kerja PLTSa teknologi biokimia dan teknologi termal. Faktorfaktor lain digunakan seperti luas area TPA Piyungan; potensi timbunan sampah harian; efisiensi proses; dan reduksi volume sampah.

\section{HASIL DAN PEMBAHASAN}

Hasil analisa sampah masuk yang sudah dilakukan di TPA Piyungan dalam satu bulan penuh menghasilkan data primer berupa jumlah kapasitas sampah masuk dari Kota Yogyakarta. Berdasarkan data primer yang didapatkan bahwa kapasitas sampah masuk Kota Yogyakarta yang menuju TPA Piyungan mencapai 16.275 ton/bulan atau setara dengan 536 ton/hari. Jumlah kapasitas sampah masuk tersebut tentunya sudah masuk dalam kategori besar karena sudah melewati batas maksimum untuk yaitu 500 ton/hari. Sumber timbunan sampah Kota Yogyakarta berasal dari sampah rumah tangga; 
pasar; industri; taman; fasilitas publik; pariwisata; dan lainlain. Tabel 1 menjelaskan tentang data-data primer dan sekunder hasil pengukuran kapasitas sampah masuk di TPA Piyungan.

TABEL I

DATA PRIMER DAN SEKUNDER MASSA SAMPAH KOTA

\begin{tabular}{|c|c|c|}
\hline Tahun & Bulan & Massa (ton) \\
\hline \multirow{8}{*}{2018} & Mei & 12.278 \\
\hline & Juni & 13.823 \\
\hline & Juli & 14.699 \\
\hline & Agustus & 16.389 \\
\hline & September & 13.614 \\
\hline & Oktober & 17.276 \\
\hline & November & 17.769 \\
\hline & Desember & 17.822 \\
\hline \multirow{4}{*}{2019} & Januari & 18.034 \\
\hline & Februari & 16.415 \\
\hline & Maret & 19.441 \\
\hline & April* & 17.744 \\
\hline
\end{tabular}

Berdasarkan Tabel 1. bulan April merupakan waktu pengambilan data primer data pengukuran sampah masuk Kota Yogyakarta ke TPA Piyungan. Berdasarkan Tabel 1. Kapasitas sampah masuk ke TPA Piyungan sebesar 17.744 ton atau setara dengan 592 ton/hari. Kapasitas sampah masuk terlihat semakin meningkat dalam beberapa waktu terakhir dari tahun 2018 sampai 2019. Hal ini berbanding lurus dengan penambahan jumlah penduduk di Kota Yogyakarta juga berbanding lurus dengan jumlah wisatawan yang berkunjung ke Kota Yogyakarta. Berdasarkan data kapasitas sampah masuk TPA Piyugnan semkain menigkat setiap waktunya. Hal ini jika dibiarkan saja juga akan merugikan lahan sekitar TPA Piyungan karena akan terus diperluas sampai tidak ada batasnya.

Solusi yang tepat untuk mereduksi volume sampah yang semakin meningkat adalah dengan pembangunan Pembangkit Listrik Tenaga Sampah (PLTSa). PLTSa merupakan jenis energi baru terbarukan (EBT) dibidang waste to energy (WtE). WtE memanfaatkan sisa kegiatan manusia (berupa sampah) untuk diolah dan dimanfaatkan energi panasnya untuk membangkitkan mesin boiler yang terhubung oleh turbin dan generator. Generator yang berputar akan menghasilkan gelombang elektromagnetik sehingga mampu untuk memproduksi listrik yang bisa didistribusikan ke rumah tangga maupun industri. Teknologi pengolahan sampah menjadi energi tentu banyak pilihannya tergantung proses kerjanya. Memilih teknologi juga perlu melalui sebuah keputusan yang tepat, sehingga penggunaan teknologi $\mathrm{WtE}$ yang terpilih sesuai dengan karakteristik sampah Kota Yogyakarta. Langkah-langkah yang dilakukan dalam memilih teknologi dengan metode GA harus sesuai dengan aturanaturan yang sudah ditentukan.

Langkah awal dalam memilih teknologi PLTSa di TPA Piyungan adalah menyusun tabel yang ditunjukkan pada Tabel 2. Dengan mengisi nilai-nilai sesungguhnya pada setiap pilihan faktor. Langkah berikutnya adalah memberikan penilaian mulai dari 1 yang artimya poor atau nilai terendah sampai dengan 5 yang artinya excellent atau nilai tertinggi pada masing-masing kolom Tabel 3. Yang menunjukkan tentang pertimbangan penilaian faktor norma pada setiap faktor-faktor pertimbangan. Nilai faktor pertimbangan bisa berbeda-beda sesuai dengan nilai sesungguhnya dari setiap faktor.

TABEL 2

PERTIMBANGAN PENILAIAN SESUNGGUHNYA SETIAP FAKTOR

\begin{tabular}{|l|l|c|c|l|l|}
\hline \multicolumn{2}{|r|}{ Faktor } & $\begin{array}{c}\text { Sampah Masuk } \\
\text { (ton) }\end{array}$ & $\begin{array}{c}\text { Luas Area } \\
\text { TPA (ha) }\end{array}$ & $\begin{array}{c}\text { Efisiensi } \\
\text { Proses }\end{array}$ & $\begin{array}{c}\text { Reduksi Volume } \\
\text { Sampah }\end{array}$ \\
\hline \multirow{2}{*}{$\begin{array}{l}\text { Ther- } \\
\text { mal }\end{array}$} & Insinerator & 536 & 16 & cepat sekali & $>100$ ton/hari \\
\cline { 2 - 6 } & Pirolisis/gasifikasi & 536 & 16 & sedang & $21-30$ ton/hari \\
\cline { 2 - 6 } & hidrotermal & 536 & 16 & cepat sekali & $50-100$ ton/hari \\
\hline \multirow{2}{*}{$\begin{array}{l}\text { Bio- } \\
\text { kimia }\end{array}$} & Anerobic digestion & 536 & 16 & lambat sekali & $<10$ ton/hari \\
\cline { 2 - 7 } & Landfill & 536 & 16 & lambat & $10-20$ ton/hari \\
\hline
\end{tabular}

TABEL 3

PERTIMBANGAN PENILAIAN FAKTOR NORMA PADA SETIAP FAKTOR

\begin{tabular}{|c|c|c|c|c|c|}
\hline \multicolumn{2}{|c|}{ Faktor } & \multirow{2}{*}{$\begin{array}{c}\text { Sampah Masuk } \\
\text { (ton) }\end{array}$} & \multirow{2}{*}{$\begin{array}{c}\text { Luas Area } \\
\text { TPA (ha) }\end{array}$} & \multirow{2}{*}{$\begin{array}{c}\text { Efisiensi } \\
\text { Proses }\end{array}$} & \multirow{2}{*}{$\begin{array}{c}\text { Reduksi Volume } \\
\text { Sampah }\end{array}$} \\
\hline Pilihan & eknologi & & & & \\
\hline \multirow{2}{*}{$\begin{array}{l}\text { Ther- } \\
\text { mal }\end{array}$} & Insinerator & 5 & 5 & 5 & 5 \\
\hline & hidrotermal & 5 & 5 & 5 & 4 \\
\hline $\begin{array}{l}\text { Bio- } \\
\text { kimia }\end{array}$ & Anerobic digestion & 5 & 5 & 1 & 1 \\
\hline
\end{tabular}

TABEL 4

PENILAIAN WEIGHTING FACTOR

\begin{tabular}{|c|c|c|c|c|}
\hline Faktor & $\begin{array}{c}\text { Sampah Masuk } \\
\text { (ton) }\end{array}$ & $\begin{array}{l}\text { Luas area } \\
\text { TPA (ha) }\end{array}$ & $\begin{array}{l}\text { Efisiensi } \\
\text { Proses }\end{array}$ & $\begin{array}{l}\text { Reduksi Volume } \\
\text { Sampah }\end{array}$ \\
\hline Weighting Factor & 5 & 5 & 3 & 5 \\
\hline
\end{tabular}


PERHITUNGAN PERKALIAN ANTARA FAKTOR NORMA DENGAN WEIGHTING FACTOR

\begin{tabular}{|l|l|c|c|c|c|}
\hline \multicolumn{2}{|r|}{ Faktor } & $\begin{array}{c}\text { Sampah Masuk } \\
\text { (ton) }\end{array}$ & $\begin{array}{c}\text { Luas Area } \\
\text { TPA (ha) }\end{array}$ & $\begin{array}{c}\text { Efisiensi } \\
\text { Proses }\end{array}$ & $\begin{array}{c}\text { Reduksi Volume } \\
\text { Sampah }\end{array}$ \\
\hline \multirow{2}{*}{$\begin{array}{l}\text { Ther- } \\
\text { mal }\end{array}$} & Insinerator & 25 & 25 & 15 & 25 \\
\cline { 2 - 6 } & Pirolisis/gasifikasi & 25 & 25 & 9 & 15 \\
\cline { 2 - 6 } & hidrotermal & 25 & 25 & 15 & 20 \\
\hline \multirow{2}{*}{$\begin{array}{l}\text { Bio- } \\
\text { kimia }\end{array}$} & Anerobic digestion & 25 & 25 & 3 & 5 \\
\cline { 2 - 6 } & Landfill & 25 & 25 & 6 & 10 \\
\hline
\end{tabular}

Langkah terakhir adalah pengambilan keputusan teknologi yang tepat di TPA Piyungan berdasarkan hasil perhitungan perkalian antara faktro norma dengan weighting factor. Hasil nilai pada Table 5. kemudian dijumlah unutk nilai masingmasing jenis teknologi. Teknologi insenerator mendapatkan nilai 90; pirolisis/gasifikasi 74; hidrotermal 85; anaerobic digestion 58; dan landfill 66. Berdasarkan hasil perhitungan nilai penjumlahan masing-masing teknologi , maka teknologi yang tepat untuk TPA Piyungan adalah teknologi insenerator.

Teknologi insenerator merupakan teknologi PLTSa dengan proses kerja berdasarkan metode termokimia. Proses kerja PLTSa dengan teknologi insenerator adalah diawali dengan sampah yang masuk ke dalam TPA Piyungan dibiarkan selama kurang lebih 3 hari untuk menurunkan kadar air sampah yang rata-rata sebesar $60 \%$. Kadar air setelah 3 hari akan menyusut menjadi sekitar $20 \%$ untuk batas minimal sampah siap masuk ke reaktor. Residu dari pembakaran sampah berupa abu atas dan abu bawah.

Sampah yang siap dibakar didalam reaktor melewati conveyor untuk dimasukkan ke mesin pencacah agar sampah menjadi terurai keukuran lebih kecil. Mesin conveyor terus bergerak untuk mengirim sampah caacahan masuk ke boiler. Sampah dalam boiler akan dibakar pada suhu di atas $1000{ }^{\circ} \mathrm{C}$. Suhu tinggi menyebabkan dioxi dalam sampah lepas ke udara, dan dioxin ditangkap dengan sistem penangkap material kecil (electrostatic precipitator). Panas dari bolir kemudian di gunakan untuk menguapkan uap air yang menggerakan turbin. Turbin yang terhubung dengan generator menggerakan generator untuk menghasilkan listrik. Listrik yang dihasilkan kemudia didistribusikan ke jaringan listrik PLN. Berdasarkan perhitungan konversi energi dari Kementerian Energi Sumber Daya Mineral Direktorat Jendral Energi Baru Terbarukan dan Konversi Energi (EBTKE) bahwa 100 ton sampah mampu menghailkan listrik sebesar 5 MW. Berdasarkan perhitungan konversi tersebut potensi jumlah massa sampah Kota Yogyakarta mampu menghasilkan listrik sebesa5 $25 \mathrm{MW}$.

\section{KESIMPULAN}

Berdasarkan data-data primer dan sekunder yang dikumpulkan dan diolah, bahwa jumlah massa sampah masuk Kota Yogyakarta ke TPA Piyungan didapatkan sebesar 592 ton/hari atau setara dengan rata-rata 17.744 ton/bulan. Luas TPA Piyungan sebesar 16 ha, maka teknologi yang tepat untuk kondisi tersebut adalah teknologi insenerator.
Teknologi insenerator dapat digunakan sebagai PLTSa dengan memanfaatkan material sampah yang mempunyai kadar air minimal 20\%. Material sampah sebagai bahan baku sistem pembangkit lsitrik prinsip kerjanya hampir sama dengan pembangkit listrik yang memanfaatkan dengan batubara. Kelebihan PLTSa dibandingkan dengan pembangkit dari batubara adalah ketersediaan raw material yang melimpah dan tidak perlu membeli untuk mendapatkannya. Berdasarkan perhitungan konversi energi dari EBTKE Kementerian ESDM bahwa massa sampah Kota Yogyakarta mampu menghasilkan potensi energi listrik sebesar $25 \mathrm{MW}$ dengan teknologi insenerator.

\section{UCAPAN TERIMA KASIH}

Terima kasih kepada Lembaga Penelitian dan Pengabdian Masyarakat (LPPM) Aswaja Center Universitas Nahdlatul Ulama Yogyakarta dan Direktorat Riset dan Pengabdian Masyarakat (DRPM) Kementerian Riset Teknologi dan Perguruan Tinggi yang sudah membiayai penelitian ini.

\section{DAFTAR PUSTAKA}

[1] A. A. Musyafiq dan B. N. Cahyo, "Pemilihan teknologi waste to energy untuk pembamgkit listrik tenaga sampah (studi kasus:TPA Mojorejo Kabupaten Sukoharjo Jawa tengah," Prosiding Seminar Nasional Sains Dan Teknologi 9, 2018, 13-18.

[2] M. Jibran, S. Zuberi, dan F. A. Shazia, "Greenhouse effect reduction by recovering energy from waste landfills in Pakistan," Renewable and Sustainable Energy Reviews, vol. 44, pp. 117-131, 2015.

[3] W. Widyawidura, dan J. I. Pongoh, "Potensi Waste to Energy Sampah Perkotaan untuk Kapasitas Pembangkit 1 MW di Propinsi DIY," Jurnal Mekanika Dan Sistem Termal, vol. 1, pp. 21-25, 2016.

[4] T. M. Ismail, K. Yoshikawa, H. Sherif, M. A. El-Salam, "Hydrothermal treatment of municipal solid waste into coal in a commercial Plant: Numerical assessment of process parameters," Applied Energy, vol. 250, pp. 653-664, 2019.

[5] D. Guppat, S. M. Mahajani, A, Garg, "Effect of hydrothermal carbonization as pretreatment on energy recovery from food and paper wastes," Bioresource Technology, vol. 285, pp. 121-129, 2019.

[6] Badan Pusat Statistik, Kota Yogyakarta Dalam Angka 2018, kota Yogyakarta: BPS, 2018.

[1] N. W. Lawrence, Social Research Methods, Qualitative and Quantitative Approach Seventh Edition, New York: AB. Boston, 2014.

[2] A. H. Pohan, Be A Smart Leader Rahasia di balik Keputusan CEO dan Manajer Hebat, Yogyakarta: Pustaka Grhatama, 2010. 